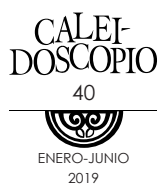

\title{
Formación de preceptores en Aguascalientes, 1860-1877
}

Training of preceptors in Aguascalientes, 1860-1877

OMAR RUIZ TREJO'

RESUMEN

En Aguascalientes la formación de preceptores respondió al esfuerzo por alfabetizar a la población al introducir preceptos como obligatoriedad, gratuidad y uniformidad. Dichas ideas comienzan a implementarse en las entidades desde los primeros años del México independiente. La capacitación de preceptores se puede insertar dentro de un proceso educativo con elementos que sugieren un tipo de federalización que se mantiene a pesar de las dificultades económicas y políticas presentadas a lo largo del siglo XIX. Reestablecido el orden republicano en el ámbito local, fue posible fomentar el ramo de instrucción pública, hecho que a su vez propició un incremento en la matrícula, por lo tanto, se presentó la necesidad de contar con un mayor número de preceptores para alcanzar una alfabetización masiva. En los años siguientes la asistencia de los preceptores a la escuela normal se volvió obligatoria y, llegado el año de 1877, los planes de estudio mostraron cambios considerables.

Palabras clave: preceptores, formación, uniformidad, escuela normal.

\section{ABSTRACT}

In Aguascalientes, the formation of preceptors responded to the effort to teach the population literacy by introducing precepts as obligatory, free and uniform. These ideas begin to be implemented in the entities from the first years of independent Mexico. The training of preceptors can be inserted within an educational process with elements that sug-

1 Universidad Autónoma de Zacatecas, México. 
gest a type of federalization that is maintained despite the economic and political difficulties presented throughout the nineteenth century. Re-established the republican order at the local level it was possible to promote the public education branch, which in turn led to an increase in enrollment, therefore, there was a need to have a greater number of preceptors to achieve mass literacy. In the following years the attendance of the preceptors to the Normal School became obligatory and arrived the year of 1877 the plans of study showed considerable changes.

Keywords: preceptors, training, uniformity, normal school.

El presente artículo tiene como objeto dar cuenta del proceso educativo que se vivió en Aguascalientes en torno a la formación de preceptores de primeras letras entre 1860-1877. El arco temporal corresponde a un primer intento por establecer una Escuela Normal en la capital del estado, teniendo como cierre el momento en que es posible considerar un mayor grado de perfeccionamiento en la normatividad, aspecto que es posible observar a partir de la modificación de los planes de estudio plasmados en leyes y reglamentos de instrucción pública locales.

Dicho lo anterior, es oportuno remitirse a los planteamientos expuestos de manera general a lo largo del siglo decimonónico para observar la relación entre la formación de preceptores con la meta propuesta por el Estado -escolarizar un mayor número de individuos-. Luz Elena Galván ${ }^{2}$ ha propuesto que a partir de la consumación de la independencia, la educación fue vista como una panacea, ${ }^{3}$ un elemento que permitiría el progreso de la nación, de manera que se buscaba ofrecer a cada habitante la libertad de conocer su posición como ciudadano y así contribuir con el orden social para, finalmente, elevar a México a la par de otros países desarrollados.

Incrementar el número de sujetos que supieran leer y escribir tenía como fin el reconocimiento de sus derechos y obligaciones para fortalecer el Estado, proceso que visto desde un tipo de historiografía de la educación se ha considerado como una necesidad latente por for-

2 Galván, Luz Elena. "En la construcción de una historia, educación y educadores durante el porfiriato", en Indios, peones, hacendados y maestros: viejos actores para un México nuevo (1821-1943), ed. Martínez, Lucía, 175, México: UPN, 1994.

3 Entendemos por panacea como solución, remedio o medicamento a todos los males. 
mar ciudadanos. ${ }^{4}$ Dentro de este consenso podemos incluir a Josefina Granja Castro, quien ha dado cuenta de que el Estado se erigió en vigía del bienestar y la seguridad social, y por lo tanto, se consideró a la escuela como el centro de la estrategia para el saneamiento social (de la ignorancia, vicios, inmoralidad e insalubridad), necesaria para conducir al país hacia la modernización, ${ }^{5}$ proceso que incita a fijar la atención tanto en la figura del preceptor como en las características de su capacitación en el periodo propuesto.

Por su parte, Rosalía Meníndez menciona que, al avanzar la segunda mitad del siglo xIX, los liberales concentraron sus esfuerzos en diseñar un proyecto educativo moderno bajo la dirección del Estado. La idea central era formar a los niños en la escuela, es decir, contar con una educación que atendiera la formación cívica del niño. ${ }^{6}$ La autora sostiene que mediante la escuela se transmiten los cimientos ideológicos de la enseñanza liberal: formar ciudadanos leales e industriosos, es decir, individuos políticos nuevos, leales a la nación que en consecuencia actuaran como agentes económicos autónomos. ${ }^{7}$

Frente a estos planteamientos, resulta pertinente enfocarse en la formación de preceptores como agentes de cambio, aspecto que visto desde el caso de Aguascalientes permite observar en qué medida se perfeccionó el oficio al incluir dentro de la reglamentación la obligatoriedad, uniformidad y gratuidad en las primeras letras, aspectos que aparecen constantemente en el discurso político de la segunda mitad del siglo XIX y que se pueden considerar como las bases de una educación moderna.

La formación de preceptores fue una respuesta inmediata a la introducción del sistema lancasteriano en México después de la Independencia. El método mutuo no era realmente nuevo, pues había sido aplicado en

4 Ríos Zúñiga, Rosalina. Formar ciudadanos. Sociedad civil y modernización popular en Zacatecas, 1821-1853. México: UNAM-Valdés Editores, 2005, 140. Anne Staples \& Josefina Zoraida Vázquez, eds., Ensayos sobre historia de la educación en México: Panorama educativo al comienzo de la vida independiente, México: El Colegio de México, 1985, p. 102.

5 Josefina Granja Castro. "Contar y clasificar a la infancia. Las categorías de la escolarización en las escuelas primarias de la ciudad de México 1870-1930", Revista Mexicana de Investigación Educativa, Vol. 14, Núm. 40, México: Comie, 2009, p. 220.

6 Rosalía Meníndez, "Nacionalismo y patriotismo, fundamentos para la formación de ciudadanos: los libros de texto de civismo para educación primaria, 1876-1921". Las disciplinas escolares y sus libros, México: Ciesas-UAEM-Juan Pablos Editores, 2010, pp. 51-52.

7 Rosalía Meníndez, "Los proyectos educativos del siglo XIX: México y la construcción de la nación", Estudios 101, Vol. X, México: UPN verano, 2012, p. 197.

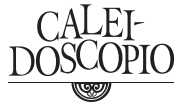


Europa desde la segunda mitad del siglo XVIII en la escuela de primeras letras de los betlemitas, una orden religiosa católica masculina. Su influencia se debió a los refinamientos hechos por Joseph Lancaster y la divulgación que dio a su obra en Inglaterra a principios del siglo XIX, lugar donde para entonces se percibió como algo innovador. ${ }^{8}$

El interés por este método se debió a varios factores, como fue la aceptación popular y oficial que gozaba en países industrializados, lo cual le confirió prestigio y muchas personas relacionaron el desarrollo europeo con el mayor nivel educativo de las masas logrado por el sistema lancasteriano. En aquella época se pensaba el método como un medio para transitar a la democracia política, puesto que los alumnos participaban más activamente en el proceso educativo y se reducía notoriamente la autoridad del maestro. ${ }^{9}$

La primera escuela normal lancasteriana se instaló en la capital de México en 1823, no obstante, al poco tiempo fue cerrada por falta de estudiantes. El Estado realizó varios intentos por crear más centros de formación, aunque fracasaron debido a la situación económica y política del país. ${ }^{10}$ Si bien se ha mencionado que existieron dificultades en aquellos años, resulta importante presentar lo que puede considerarse un antecedente directo para el caso de Aguascalientes.

La historiografía regional proporciona datos para dar seguimiento a personajes que se ubican como originarios del estado. Al hablar de los esfuerzos dedicados para formalizar la educación mediante la capacitación de preceptores de primeras letras, es necesario realizar un acercamiento a nuestro espacio de estudio; por tal motivo, es importante remitirnos al estado de Zacatecas, al cual Aguascalientes estuvo integrado como uno de sus partidos. Al adoptarse el sistema lancasteriano fue necesario abrir un establecimiento dedicado a la formación de preceptores en dicho estado. Una vez fundada la Escuela Normal conocida como "La Constitución", en 1825, los primeros en ser enseñados con la nueva moda pedagógica serían los preceptores de las dos escuelas con que contaba la ciudad de Zacatecas. ${ }^{11}$

8 Staples, Anne, "Panorama educativo", op. cit. p. 103.

9 Idem.

10 Luz Elena Galván, "En la construcción de una historia...", op. cit., p. 176

11 Leonel Contreras Betancourt, Escuelas Lancasterianas de Zacatecas en la primera República Federal, 1823-1835, México: Universidad Pedagógica Nacional, 2005, pp. 193-194. 
La implementación del sistema mutuo no fue como se esperaba. Ante esta situación, René Amaro Peñaflores ${ }^{12}$ ha señalado que a pesar de la enseñanza que se ofrecía, el entusiasmo por el método lancasteriano tuvo limitantes impuestos por la realidad, de allí que la Escuela Normal de enseñanza mutua en Zacatecas "no lograba convocar a sujetos aptos para capacitarlos como preceptores, a esto se debe que sólo siete personas hayan recibido el primer curso, así mismo continuó esta situación y para 1832 solamente asistieron tres personas."13

En aquellos años se contaba con pocos preceptores instruidos y examinados, de Aguascalientes sólo se menciona un tal José Ma. González; ${ }^{14}$ para 1833 asistió a la Escuela Normal de la Constitución otro preceptor hidrocálido de nombre Tiburcio Medina, este personaje se describe como originario del ayuntamiento de Rincón de Romos. ${ }^{15}$ Ante la falta de alumnos se ha concluido que el funcionamiento de la Escuela Normal de La Constitución fue intermitente, debido a la inestabilidad que se vivió en el país durante los años siguientes; ${ }^{16}$ no obstante, estos datos se pueden considerar como un referente en cuanto a la formación de preceptores hidrocálidos previo a la erección de Aguascalientes como estado de manera constitucional en 1857, circunstancia que implicó replantear el renglón educativo.

UN PRIMER INTENTO POR FORMAR PRECEPTORES EN AGUASCALIENTES

Para 1860 el gobierno del estado comenzó a fomentar por todos los medios posibles el establecimiento de escuelas oficiales para la instrucción de primeras letras, el proyecto resultaba algo ambicioso si se considera el costo que representaba la apertura de ocho establecimientos de instrucción primaria que se planeaban para la capital. ${ }^{17}$ Debido a la necesidad de atender adecuadamente los planteles existentes y los que se proyectaba abrir, se instaló una escuela normal

12 René Amaro Peñaflores, La educación popular en Zacatecas. De las primeras letras a las escuelas de artes y oficios: trabajadores, pobreza y laicización, México: UAZ-SPAUAz, 2017, p. 81.

13 Idem.

14 Contreras Betancourt, Leonel, "La Escuela Normal Lancasteriana", op. cit., p. 272.

15 Ibidem, p. 273.

16 Amaro Peñaflores, René, La educación popular, op. cit., p. 81.

17 Archivo del Cabildo de Aguascalientes, Fondo Digital Actas de Cabildo, actas 20 y 21 , 1860. (En adelante: ACA-FDAC).

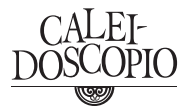


para hombres en la sala de la casa que habitaba el profesor de la Escuela Principal, ${ }^{18}$ conocida como de Cristo. ${ }^{19}$ Su objetivo consistía en dotar de herramientas pedagógicas a las personas que estaban a cargo de las escuelas, como también para quien decidiera en un futuro ejercer tal oficio.

En 1861 las posibilidades para los preceptores eran prometedoras debido al número de establecimientos, tanto públicos como particulares, que había para entonces; por ejemplo, en la capital se contaba con 15 escuelas para niños con una matrícula de 699 alumnos y 5 escuelas para niñas con 379 alumnas, el total de escuelas en el estado era de 25 para niños, con una matrícula de 1140 alumnos. Para las niñas había 8 establecimientos, con un total de 427 alumnas. En suma, existían 33 escuelas en todo el estado con un total de 1597 alumnos. ${ }^{20}$ De acuerdo con estos datos, la existencia de una escuela normal proporcionaba la posibilidad de atender un mayor número de niños y, al existir una vacante, difícilmente faltaría quien se hiciera cargo.

En 1862 se echaron a andar dos escuelas de niñas, una dirigida por el profesor José María González, quien recibía como sueldo 15 pesos mensuales. La segunda estaba a cargo de la Sra. Loreto Esparza. ${ }^{21}$ De acuerdo con las actas de cabildo, la economía no gozaba de suficiente holgura y los dictámenes educativos oficiales pronto se desmoronaban, entre tanto, desapareció la Escuela Normal y algunos establecimientos públicos de primeras letras. ${ }^{22}$

El gobierno del estado pronto se dio cuenta de la dificultad que representaba la labor educativa e intentó echar mano de otros actores, fue así que se propuso solicitar el apoyo tanto de particulares como de la iglesia católica para evitar que otras escuelas cerraran sus

18 Idem.

19 Esta escuela se ubicaba en la calle que va de la plaza principal al templo de San Diego, al día de hoy conocida como andador Juárez. Dicho espacio aún se reconoce con el mismo nombre y funciona como sala de exposiciones temporales y para eventos relacionados con la cultura a cargo del ayuntamiento de la cuidad.

20 Isidoro Epstein, Cuadro Sinóptico de Aguascalientes, Aguascalientes, Imprenta de Ávila y Chávez, 1861, citado en Gómez Serrano, Jesús, Aguascalientes en la historia: 1786-1920, Sociedad y Cultura, México: Gobierno del Estado de Aguascalientes-Instituto de investigaciones Dr. José María Luis Mora, México, 1988, p. 251.

21 ACA-FDAC, 1862, actas 4 y 17.

22 Idem. 
puertas. ${ }^{23}$ En cuanto al apoyo solicitado, se puede decir que no existe suficiente evidencia documental para demostrar que fue atendida la solicitud, aunque se puede sugerir que no procedió debido a su inminente cierre.

\section{EL RESTABLECIMIENTO DE LA ESCUELA NORMAL; ENTRE LA FORMACIÓN DE PRECEPTORES Y LA UNIFORMIDAD DE LA ENSEÑANZA}

Al reglamentarse la instrucción pública en 1863, se enfatizó en la uniformidad de la enseñanza y el método continuó siendo el sistema lancasteriano. El restablecimiento de la Escuela Normal tendría como objetivo capacitar preceptores de instrucción primaria ${ }^{24}$ y favorecer la tarea de escolarizar a los habitantes mediante un plan de estudios único y la utilización de las mismas herramientas de enseñanza para todos los planteles. Si bien se define el modelo, el rigor en cuanto a la aplicación dependió de la libertad que se otorgó para ser utilizado, pues se dejó a la inteligencia de los preceptores el modo de combinarlo con el fin de lograr el mayor éxito posible, ${ }^{25}$ es así que la impartición de clases aún podía variar entre un establecimiento y otro, por tal motivo la uniformidad propuesta se encontraba en proceso de construcción, de manera que tendría mayor sentido la creación de una escuela normal.

\section{a. La habilitación de preceptores y su ingreso a la Escuela Normal}

Como requisito para ingresar a la Escuela Normal de Aguascalientes desde 1863 se estableció que el aspirante debía presentar el título de preceptor de segunda clase, que expedía la Junta de Instrucción Pública; esta instancia poseía la facultad de habilitar y otorgar dicho documento a los candidatos que fuesen necesarios para el servicio de las escuelas municipales. ${ }^{26}$

La función de los preceptores de segunda clase era fungir como ayudantes en las escuelas de primer orden (básicamente éstas se ubicaban en la capital del estado) siempre que éstas excedieran de cincuenta alumnos; dichos personajes contaban con la posibilidad de

23 Idem.

24 La Revista, Julio 16 y 19 de 1863. "Reglamento de Instrucción de 1863".

25 Idem

26 Idem

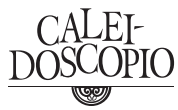


combinar esta actividad con su formación en la Escuela Normal. Por otra parte, podían estar a cargo de una de las escuelas de segundo orden (estas se establecían principalmente en los partidos y se caracterizaban por impartir una enseñanza más rudimentaria), en las que se enseñaba lectura y escritura perfectas, aritmética práctico-razonada y gramática castellana, el curso debía durar dos años, a diferencia de las escuelas de primer orden, en las que se contemplaban tres cursos y un mayor número de materias. ${ }^{27}$

¿Pero en qué consistía la habilitación?: es pertinente decir que tanto en años anteriores como para el periodo resulta hasta cierto punto riesgoso hablar de preceptores formados y titulados en una escuela normal, por lo tanto incluimos la categoría de "preceptores habilitados" propuesta por Ángel Mato Díaz, ${ }^{28}$ quien menciona para el caso de España algunos requisitos para conseguir el cargo como preceptor de primeras letras. Los aspirantes debían superar un examen ante la Junta Provincial nombrada por el jefe político y así habilitarlos para desempeñar las funciones destinadas a la enseñanza. Si bien la reglamentación en Aguascalientes no ahonda en este aspecto, tal referencia sugiere un mecanismo similar donde los aspirantes se debían sujetar a una examinación ante la Junta de Instrucción Pública y así recibir la habilitación para ejercer dicha función.

b. Contenido de los cursos para la enseñanza normal en 1863

Los planes de estudio para obtener el título de primera clase en la Academia o Escuela Normal comprendían dos cursos, cuyo tiempo no debía de exceder dos años y las materias que se debían cursar se pueden observar en el cuadro 1.

27 Idem.

28 Ángel Díaz Mato, "Las escuelas y los maestros de primeras letras siglo XIX", Revista de Formación del Profesorado e Investigación Educativa, núm. 23, verano, 2010, p. 27. 


\section{Cuadro 1}

MATERIAS A CURSAR EN LA ESCUELA NORMAL, 1863

\begin{aligned} & \hline \multicolumn{1}{c}{ Primer curso } \multicolumn{1}{c}{ Segundo curso } \\ & \hline Aritmética práctico-razonada Geometría aplicada a las artes y oficios \\ & Sistema métrico decimal Cosmografía \\ & Álgebra (hasta ecuaciones de segundo grado) Geografía general \\ & Gramática castellana Geografía especial de la República Mexicana \\ & Historia sagrada Historia de México \\ & Cartilla política Urbanidad \\ & \hline\end{aligned}

Fuente: La Revista, 16 y 19 de julio de 1863.

El proyecto de Escuela Normal de 1863 contempla la formación tanto de hombres como de mujeres, a diferencia de aquel primer intento en 1860. Se indicaba que las señoras preceptoras que concurrieran a la Escuela Normal "estaban obligadas a obtener el título de primera clase, a estudiar la mayoría de las materias e incluso la economía doméstica -esto a pesar de no estar contemplada de manera oficial en el plan de estudios-, pero con excepción del Álgebra y la Geometría". 29

Con relación a las materias asignadas para las mujeres, Oresta López Pérez ${ }^{30}$ ha explicado que la diferenciación del contenido que debían estudiar para acceder al cargo de preceptoras devela límites y orientaciones claras respecto a la forma de acotar e interpretar un tipo de "ciudadanía femenina", es decir, de formación moral y cívica, esto no obstante que a partir de la segunda mitad del siglo XIX los discursos liberales llamaban a la igualdad educativa. ${ }^{31}$

Para el caso de Aguascalientes, se tiene que la Constitución local de $1861^{32}$ únicamente contempla como ciudadanos a quienes fueran

29 La Revista, julio 16 y 19 de 1863.

30 Oresta López Pérez, "Currículum sexuado y poder: miradas de la educación liberal para hombres y mujeres durante la segunda mitad del siglo XIX en México", Revista Relaciones, vol. XXIX, núm. 113, El Colegio de Michoacán, invierno 2008, p. 36.

31 Idem.

32 H. Congreso del Estado, LII Legislatura, "Constitución política del estado de Aguascalientes de 1857", en Las Constituciones de Aguascalientes, México, 1986, p. 5. 
nacidos y avecindados en el estado, siempre y cuando contaran con 18 años siendo casados y 25 para los solteros. ${ }^{33}$ De manera independiente a la ausencia de las mujeres en el texto, su actuación en la enseñanza tiene implicaciones para considerar un tipo de ciudadanía, sobre todo, si se considera que el empleo se otorgaba mediante el nombramiento de las autoridades, lo cual generaba una relación donde ellas debían cumplir con deberes y obligaciones como educadoras frente al Estado; visto de esta manera, dicha relación nos sugiere elementos para considerar esto como una ruta para reflexionar en torno a la mujer en dicha categoría.

La educación de las mujeres se centró en la formación del ideal femenino a través de la instrucción doméstica y la moralidad, en ocasiones sustentada en la ideología católica que definió la construcción de las virtudes morales, el comportamiento, las normas, valores y costumbres que fueron reforzadas y perfeccionadas dentro del hogar. La educación de las hijas pretendía formar mujeres que, a su vez, se convirtieran en educadoras. ${ }^{34}$ En este punto cobra importancia el hecho de incluir la historia sagrada como una de las materias a cursarse; es cierto, sus contenidos eran religiosos pero entendemos que sus fines eran civiles. Por otra parte, no se puede perder de vista que, al exigirles obtener el título de primera clase, a la larga generará la posibilidad para que la mujer gane terreno como educadora frente a los hombres, tema que aún adolece de estudios para Aguascalientes y merece mayor atención para explicar ese proceso.

En contraposición, en el segundo curso aparece la materia de geometría aplicada a las artes, que como se menciona líneas atrás era incluida únicamente dentro del plan de estudios para los hombres, lo que lleva a proponer que su finalidad radicaba en proporcionar herramientas con las cuales estos preceptores pudieran orientar a los niños a insertarse dentro del espacio productivo -tal vez como artesanos-, puesto que el objeto de la instrucción fue formar personas industriosas para impulsar el progreso de la nación.

33 Idem.

34 María del Carmen Gutiérrez, "De la educación de las niñas a la mujer educadora en el siglo XIX", en Miradas entorno a la educación de ayer, ed. Luz Elena Galván, 115-116, México: COMIE-U de G., 1997. 
c. El alumno de la normal y su permanencia durante sus estudios

Para permanecer como alumno en la Escuela Normal, el estudiante estaba obligado a conducirse con la urbanidad y moralidad suficientes que más tarde le hicieran digno de presidir la educación de la juventud; debía cumplir con todas las tareas que el director le señalara, principalmente asistir a la cátedra, todo con la más estricta puntualidad. ${ }^{35} \mathrm{El}$ alumno solo podía faltar a la asistencia con anuencia del director, pero la licencia que este concedía nunca debía exceder de ocho días; "la que pase de este término sólo podrá ser concedida por la Junta inspectora". ${ }^{36}$

Sólo eran motivos justificados para ausentarse: enfermedad, ocupación imprescindible o salida imprevista del lugar. En cualquier otra circunstancia, el director o la junta harían un extrañamiento al alumno, ${ }^{37} \mathrm{o}$ en otras palabras se condicionaría su permanencia en el plantel. La disciplina inculcada en este de establecimiento proporciona una idea del perfil que debía mostrar el preceptor ante los alumnos y la sociedad, rasgos que ofrecen una imagen del prototipo de ciudadano que había de reproducirse en las aulas teniendo como resultado un modelo idealizado a seguir.

Algunas complicaciones se presentaron en los años siguientes, durante el Segundo Imperio (1863-1866); en Aguascalientes el gobierno local se caracterizó por las dificultades de los personajes que ocuparon cargos en la administración y como consecuencia se vio afectado el renglón educativo. Un testimonio de la época menciona que "cuando los liberales abandonaban la plaza", quienes asumieron el poder en Aguascalientes "no procuraron dar vida al ramo de instrucción, mucho menos tomaron parte en su fomento", sino todo lo contrario. Entre estos personajes se ubica a los señores "Cayetano Basave, Francisco Ruiz de Esparza y Manuel Arteaga, quienes en los años de 1864, 1865 y parte de 1866 figuraron como prefectos políticos del entonces Departamento de Aguascalientes". ${ }^{38}$

Previo a 1863 se había presenciado el cierre de escuelas en Aguascalientes, pero las críticas respecto a la falta de establecimien-

35 La Revista, julio 16 de 1863.

36 Idem

37 Idem.

38 Jesús Bernal Sánchez, Apuntes históricos, geográficos y estadísticos del Estado de Aguascalientes, México: Signo Imagen, 2005, p. 136.

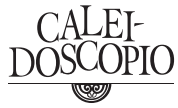


tos le adjudicaban todos los males al gobierno imperial; en enero de 1865 un medio impreso local publicó que la capital tenía más de un año sin escuelas para niñas y con dificultad el ayuntamiento mantenía abierto un plantel para niños, aunque carente de mobiliario y útiles. ${ }^{39}$

Al finalizar el año de 1866, los republicanos volvieron a ocupar la capital del estado ${ }^{40}$ y para el año siguiente se logró reorganizar el gobierno local, una de las primeras medidas fue fomentar la enseñanza como tarea prioritaria. El gobernador Jesús Gómez Portugal manifestaba en enero de 1867 que:

uno de los deberes más imperiosos de todo gobierno es promover la instrucción pública por todos los medios legítimos a su alcance, pues la base de toda sociedad culta y la verdadera libertad son tanto más sólidas cuando es mayor el número de ciudadanos instruidos. ${ }^{41}$

Atendiendo a lo expuesto por el gobernador, todo indicaba que en el fondo se mantenía presente la intención de implementar medidas en favor de la formación de preceptores para asegurar la escolarización del pueblo.

\section{EL RUMBO DE LA ENSEÑANZA NORMAL DE 1867 A 1877}

A consecuencia del estado que guardó la instrucción pública debido a los sucesos anteriores al regreso de los republicanos al gobierno, fue necesario intensificar algunas medidas, de manera que la formación de preceptores tomara un papel preponderante ante tal escenario. Para enero de 1867, en Aguascalientes se promulgó la Ley de Instrucción Pública para el Estado, a Ignacio T. Chávez le tocó ejecutarla como presidente de la junta, dicho documento incluyó la formación obligatoria de los preceptores. ${ }^{42}$

39 La Libertad de México, enero 8 de 1865.

40 Vicente Ribes Iborra, "La educación Aguascalentense en el Porfiriato" en Páginas sueltas, México: UAA-Centro de Ciencias Sociales y Humanidades, 2000, p. 67.

41 El Republicano, enero 3 de 1867, p. 2.

42 Archivo Histórico del Estado de Aguascalientes (en adelante AHEA), Fondo educación, "Circular a los preceptores de primeras letras", julio 2 de 1867, Caja 1, Expediente 2, f. $16, \mathrm{f}$. 
Conforme a dicha ley, el Sr. Chávez manifestaba que los preceptores de primeras letras de las escuelas en el estado debían contar con el título de primera clase y a nuestro juicio esta disposición oficial tenía como finalidad contribuir al fomento de la Escuela Normal, pues proponemos que, al ser obligatoria la concurrencia de los niños, se procuraba que la enseñanza fuera lo más adecuada, lejos de cualquier improvisación, por lo tanto, la ley era muy clara en su propósito:

Teniendo presente la junta que presido el contenido del artículo $6^{\circ}$ de la ley del 11 de enero de este año, se recuerda a los preceptores y preceptoras de las escuelas públicas y privadas de esta ciudad, que van anotados al margen, que los que no tienen título están obligados a concurrir a la escuela normal que está establecida en la de agricultura, bajo el concepto que los que tengan, deberán exhibirlo al que suscribe, dentro del término de tres días y obrando de aquella manera den cumplimiento a lo que prescribe dicho artículo cuyo tenor es el siguiente:

Art. $6^{\circ}$. Los preceptores o preceptoras de primeras letras que actualmente existen al frente de los establecimientos, o sean colocados en el curso del presente año y que no tengan título, están obligados a concurrir a la Escuela Normal y a presentar examen al fin del mismo año presente. ${ }^{43}$

Ante tal medida no queda duda sobre la intención de lograr un mayor grado de preparación y contar con preceptores idóneos a partir de una acción institucional en favor de la instrucción pública. Entre los preceptores que aparecen al margen del documento encontramos a "Gorgonio Venegas, Urbano N. Marín, Cirilo Posada, Eduarda Leaton, José María Guerrero, Gregorio Jiménez, Rafael Medina, Ignacio Martínez y la Sra. Loreto Lira". ${ }^{44}$

Para instrumentar la ley del 11 de enero de 1867 se creó el Reglamento de Instrucción Primaria en mayo del mismo año, ahí se estipula que la Escuela Normal "tiene por objeto no sólo formar profesores de primeras letras, sino también uniformar la enseñanza en el estado". ${ }^{45}$ Para lograr tal propósito continuó como oficial el sistema lancasteriano,

\footnotetext{
43 Idem.

44 Idem.

45 HEA, Fondo Poder Legislativo, Folleto: Reglamento de Instrucción Primaria, Caja 7, Expediente 1, 1867, p. 10.
}

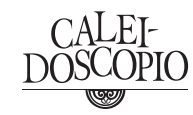


ahora "con las reformas que la Junta de Instrucción determinara a propuesta de los preceptores de primer orden" ${ }^{46}$ quienes al contar con mayor preparación y experiencia podían considerar lo más adecuado para transmitir la enseñanza con los conocimientos pedagógicos y la experiencia frente a grupo.

Aunado a lo anterior, podemos decir que para este año se observa un avance respecto a la aplicación del método de enseñanza, pues ahora se parte de un consenso en favor de realizar las reformas o adaptaciones necesarias, contrario a lo expuesto anteriormente, donde se dejaba a la inteligencia de cada preceptor la forma de aplicarlo. La duración de los cursos que debían adquirirse en la Escuela Normal continuó siendo no mayor a dos años, tal como se estipulaba desde 1863; las materias para este momento se muestran en el cuadro 2.

Cuadro 2

MATERIAS DE LA EsCUELA NORMAL, 1867

\begin{aligned} & \hline Primer curso Segundo curso \\ & \hline Gramática general Elementos de cronología \\ & Álgebra hasta las ecuaciones de segundo grado Elementos de historia universal y del país \\ & Geografía Elementos de economía política \\ & Pedagogía Idioma francés \\ & \hline\end{aligned}

Fuente: AHEA, Fondo Poder Legislativo, Folleto: Reglamento de Instrucción Primaria, Caja7, Expediente 1, 1867, pp. 10-11.

Un cambio importante que observamos dentro del primer curso fue incluir la materia de pedagogía y aunque no se especifica su contenido, probablemente uno de sus ejes fue el sistema lancasteriano. Por su parte la actuación de los preceptores en Aguascalientes fue bastante productiva para la educación de los niños, pues no dependían de los materiales existentes, incluso generaron algunos textos propios, tal es el caso de Gorgonio Venegas Castro, quien ante el deseo de ser útil dedicó su tiempo a la actualización de un compendio de aritmética para las escuelas de primeras letras, basado en textos utilizados por

46 Idem. 
aquellos años como el de Mathieu de Fossey, Bourdon Vallejo, Lacroix y Rubeaux. ${ }^{47}$

Debemos agregar que para 1868 los preceptores reflexionaban sobre la forma de aplicar el método mutuo. La aplicación cotidiana del sistema lancasteriano consistía en que los alumnos más avanzados fungían como monitores enseñando a otros de manera adecuada lo que ya sabían, tal como se difundió desde sus primeros años; no obstante, el problema que visualizaron radicaba en que era tedioso para los niños dedicarle bastante tiempo a una sola materia, por tal motivo propusieron que el sistema mutuo fuera simultáneo; en esta modalidad encontraban mayor ventaja pues este "consiste en proporcionar una instrucción a la vez de diferentes ramos". 48

El esquema en cuanto al plan de estudios para entonces sería aplicado tanto para hombres como para mujeres y no marca una diferencia por sexo como sucedió anteriormente. En comparación con la propuesta de 1863 , se aprecia una reducción de materias, lo cual se debió a que éstas se incluyeron en el examen para habilitar preceptores y obtener el título de segunda clase, requisito indispensable para el ingreso a la normal o para obtener el cargo de preceptor en un establecimiento de segundo orden (cuadro 3).

\section{Cuadro 3}

MATERIAS CONTEMPLADAS EN EL EXAMEN PARA PRECEPTOR DE SEGUNDO ORDEN PARA 1867

\begin{tabular}{cllll}
\hline Primer año & \multicolumn{1}{c}{ Segundo año } & Tercer año & \multicolumn{1}{c}{ Cuarto año } & \multicolumn{1}{c}{ Quinto año } \\
\hline Lectura & $\begin{array}{l}\text { Lectura y escritura } \\
\text { perfectos }\end{array}$ & Escritura & Escritura & Escritura \\
Escritura & $\begin{array}{l}\text { Las cuatro reglas fun- } \\
\text { damentales de arit- } \\
\text { mética para enteros y } \\
\text { quebrados }\end{array}$ & patrio & Las dos primeras & Las dos últimas \\
& & & castellana & partes de gramática \\
& & & castellana
\end{tabular}

47 AHEA, Fondo Educación, "Aritmética de Gorgonio Venegas", agosto 10 de 1867, Caja 1, Exp. 12, f., 2, f.

48 AHEA, Fondo Educación, agosto 8 de 1868, Caja 1, expediente 32, f. 28, v. 
continuación de tabla

\begin{tabular}{lllll}
\hline \multicolumn{1}{c}{ Primer año } & Segundo año & Tercer año & \multicolumn{1}{c}{ Cuarto año } & \multicolumn{1}{c}{ Quinto año } \\
\hline $\begin{array}{l}\text { Conocimien- } \\
\text { to de los } \\
\text { números y } \\
\text { cantidades }\end{array}$ & $\begin{array}{l}\text { Elementos de historia } \\
\text { sagrada }\end{array}$ & $\begin{array}{l}\text { Terminación de la } \\
\text { aritmética }\end{array}$ & Cartilla política & $\begin{array}{l}\text { Sistema métrico-de- } \\
\text { cimal }\end{array}$ \\
$\begin{array}{l}\text { Conocimien- } \\
\text { to de los } \\
\text { números y } \\
\text { cantidades }\end{array}$ & Urbanidad & Repetición de la arit- & $\begin{array}{l}\text { Dibujo natural, y } \\
\text { nociones de geo- }\end{array}$ \\
& & mética & metría \\
& & Nociones de álgebra, & Dibujo lineal \\
& & geometría y dibujo & \\
& & lineal & \\
& & Dibujo natural & \\
\hline
\end{tabular}

Fuente: AHEA, Fondo Poder Legislativo, Folleto: Reglamento de Instrucción Primaria, Caja7, Expediente 1, 1867, pp.4-5.

El objetivo de lograr la uniformidad de la educación presentó dificultades relacionadas con la falta de preparación de algunos ayudantes, quienes en teoría debían contar con título de segunda clase. Vale la pena señalar que para 1868 se detectó que en "la Escuela de Niños No. 3, situada en el barrio de San Marcos", dicho establecimiento contaba "con cerca de doscientos niños", que no habían ingresado de manera simultánea, sino en diferentes épocas del año, "de ahí que la enseñanza no lograba ser uniforme, sobre todo cuando el director no contaba con un ayudante [con] cuyo auxilio fueran sin duda mayores los adelantos". ${ }^{49}$

Cabe señalar que al hablar de una de las escuelas importantes de la capital respecto a su matrícula, aún se contaba con personas poco preparadas, de manera que esto justifica la intención por fomentar la obligación de asistir a la escuela normal, si bien no se pedía explícitamente que se destituyera al ayudante, se sugería contar con alguien mejor capacitado "como los que trabajan en otros establecimientos",

49 AHEA, Fondo Educación, "Informes y estados de las escuelas de la capital", 1868, Caja 1, expediente 32, f. 16, f., f. 16, v. y f. 17, f. 
ya que así "serían más notables los adelantos al verificarse los exámenes posteriores"..$^{50}$

El reto por lograr la uniformidad de la enseñanza se reafirmó en 1869 con la continuidad de la Escuela Normal, la Ley de Instrucción de este año reitera que los preceptores de los establecimientos públicos debían asistir de manera forzada.$^{51}$ En este momento se planeaba, además, establecer un colegio de niños (el cual no llegó a concretarse), que tendría el carácter de escuela normal, donde podrían asistir los preceptores de las escuelas de género masculino. ${ }^{52}$ En dicha ley se menciona que cualquier persona sin distinción alguna podía ejercer el profesorado en escuelas tanto públicas como privadas, siempre y cuando presentara su título de primera clase; de no tenerlo había que presentar un examen propuesto por la junta en las instalaciones Escuela Normal y en cuanto a los cursos continuó vigente lo previsto en la reglamentación anterior.

Respecto a las medidas implementadas en favor del fomento a la instrucción, podemos ver que se presentó un avance considerable al paso de algunos años: para 1874 ya se contaba con "27 escuelas públicas en todo el estado, con una matrícula de 2,253 niños y 1,072 niñas, lo que daba un total de 3,325 educandos", ${ }^{33}$ esto se puede traducir en oportunidades para los preceptores en cuanto a su inserción laboral.

La capacitación y formación de preceptores se llevó en el mismo tenor sin modificarse por casi ocho años. Fue hasta 1877 que se discutieron nuevamente los temas de instrucción pública, como resultado salió a la luz el Proyecto de Ley de Instrucción Pública del Estado Libre y Soberano de Aguascalientes. ${ }^{54}$ En este ya se habla de dos escuelas normales costeadas con los fondos del estado: una para señoritas y otra para varones; éstas comenzarían sus actividades con las mejoras señaladas a partir del 16 de septiembre. Respecto a la reglamentación, se mantuvo vigente la de 1867 en todo lo que no se opusiera a la nueva ley, de manera que no dejó de ser obligatoria la concurrencia de los preceptores a la Escuela Normal.

50 Idem.

51 AHEA, Fondo Poder Legislativo, "Proyecto de Ley de Instrucción Primaria", Caja 5, Expediente 31, 1869, f. 3, v.

52 Ibidem, f. 4, f.

53 José Díaz Covarrubias, La instrucción pública en México, México: Imprenta del gobierno, en Palacio a cargo de José M. Sandoval, 1875, p. 4.

54 El Republicano, mayo de 1877.

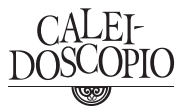


En 1877, la formación en dichas escuelas normales cobró mayor formalidad y especialización, cada escuela contaba con un plan de estudios más completo y enfocado a cada sexo, la duración sería de cuatro años para la escuela de varones y de cinco años en la normal de niñas.

\section{Cuadro 4}

ESTUDIOS EN LA ESCUELA NORMAL DE VARONES

\begin{tabular}{llll}
\hline \multicolumn{1}{c}{ Primer año } & \multicolumn{1}{c}{ Segundo año } & \multicolumn{1}{c}{ Tercer año } & \multicolumn{1}{c}{ Cuarto año } \\
\hline $\begin{array}{l}\text { Gramática castellana } \\
\text { Aritmética superior } \\
\text { teórico-práctica }\end{array}$ & Teneduría de libros & Métodos de enseñanza & Cosmografía \\
& & & $\begin{array}{l}\text { Geografía general } \\
\text { yespecialmente de } \\
\text { Ejercicios caligráficos }\end{array}$ \\
& Principios de álgebra & Migiene & Primer año de francés \\
& hasta las ecuaciones de & Segundo año de Instituto Científico & francés en el Instituto \\
& segundo grado & Literario & Científico Literario \\
Urbanidad & Geometría práctica & Dibujo & \\
Dibujo & Dibujo & & \\
\hline
\end{tabular}

Fuente: El Republicano, mayo de 1877.

Cuadro 5

ESTUdIOS EN LA ESCUELA NORMAL DE NIÑAS

\begin{tabular}{|c|c|c|c|c|}
\hline Primer año & Segundo año & Tercer año & Cuarto año & Quinto año \\
\hline $\begin{array}{l}\text { Gramática } \\
\text { castellana }\end{array}$ & Aritmética & $\begin{array}{l}\text { Elementos de cosmo- } \\
\text { grafía }\end{array}$ & Economía doméstica & Métodos de enseñanza \\
\hline $\begin{array}{l}\text { Ejercicios } \\
\text { de lectura }\end{array}$ & Principios de álgebra & Geografía & $\begin{array}{l}\text { Deberes de la mujer } \\
\text { en sociedad }\end{array}$ & Segundo año de inglés \\
\hline $\begin{array}{l}\text { Correspondencia } \\
\text { epistolar }\end{array}$ & $\begin{array}{l}\text { Geometría práctica, } \\
\text { aplicada al corte de } \\
\text { vestidos }\end{array}$ & $\begin{array}{l}\text { Cronología e historia } \\
\text { general }\end{array}$ & $\begin{array}{l}\text { Medicina e higiene } \\
\text { doméstica }\end{array}$ & Música y dibujo \\
\hline $\begin{array}{l}\text { Primer año } \\
\text { de francés }\end{array}$ & Teneduría de libros & Historia de México & Primer año de inglés & $\begin{array}{l}\text { Repetición de las materias } \\
\text { del año anterior }\end{array}$ \\
\hline \multirow[t]{2}{*}{ Música y dibujo } & Segundo año de francés & Italiano & Música y dibujo & Labores manuales \\
\hline & Música y dibujo & Música y dibujo & & \\
\hline
\end{tabular}

Fuente: El Republicano, mayo de 1877. 
En suma, podemos decir que al transcurrir estos años la enseñanza normal en Aguascalientes muestra avances considerables. En este lapso permanece en la normatividad la obligación que los preceptores tenían de prepararse y obtener un título. Durante esos años se puede observar tanto la intención por uniformar la enseñanza como por aumentar las capacidades de los preceptores; esto puede constatarse con el incremento de los contenidos, mostrado para los exámenes de habilitación de los preceptores de segunda clase y las modificaciones en los cursos de la Escuela Normal, aunque también es cierto que en la práctica algunos ayudantes carecían de tal reconocimiento.

La duración de los estudios en la Escuela Normal tendió a ser más amplia y con un plan cada vez más completo. A partir de la preparación que se ofrecía, los métodos pedagógicos tuvieron la posibilidad de ser comprendidos al grado que también existió la posibilidad de discutir y plantear mejoras para ponerlas en práctica, lo cual se confirió exclusivamente a quienes contaban con título de primera clase; en este sentido existe una revaloración del oficio y el reconocimiento a los preceptores más experimentados.

En cuanto a las materias que debían aprender tanto jóvenes como señoritas será hasta 1877 que aparece un plan destinado para cada sexo con la finalidad de orientar el perfil de los preceptores hacia actividades definidas. Para ese momento podemos agregar que la enseñanza normal llega a un mayor grado de formalidad y se propone aumentar a dos el número de establecimientos de enseñanza normal, uno para cada sexo. Con todo esto podemos decir que en Aguascalientes se presenció un constante movimiento generado por la mejora educativa que exigía la enseñanza obligatoria de los niños y jóvenes, lo cual incide en el perfeccionamiento de preceptores para así contribuir en parte con el proceso de institucionalización de la instrucción de primeras letras en el estado, lo cual es posible en la medida en que el estado asume la responsabilidad de ofrecer la instrucción a los habitantes, aspecto que, en términos generales, dará la pauta para sentar las bases de una educación moderna. 


\section{FUENTES CONSULTADAS}

Documentales

Archivo del Cabildo de Aguascalientes.

Fondo Digital Actas de Cabildo, (ACA-FDAC).

Archivo General Municipal de Aguascalientes (AGMA).

Fondo histórico: Educación.

Archivo Histórico del estado de Aguascalientes (AHEA).

Fondo: Poder Legislativo.

Fondo: Educación.

Fondo: Folletería.

\section{Periódicos}

La Revista.

El Porvenir.

El Republicano.

\section{REFERENCIAS}

Amaro Peñaflores, René. La educación popular en Zacatecas. De las primeras letras a las escuelas de artes y oficios: trabajadores, pobreza y laicización, México: UAZ-SPAUAZ, 2017.

Anne Staples \& Josefina Zoraida Vázquez, eds. Ensayos sobre historia de la educación en México: Panorama educativo al comienzo de la vida independiente. México: El Colegio de México, 1985.

Bernal Sánchez, Jesús. Apuntes históricos, geográficos y estadísticos del Estado de Aguascalientes, México: Signo Imagen, 2005.

Contreras Betancourt, Leonel. Escuelas Lancasterianas de Zacatecas en la primera República Federal, 1823-1835. México: Universidad Pedagógica Nacional, 2005.

Díaz Covarrubias, José. La instrucción pública en México. México: Imprenta del gobierno, en Palacio a cargo de José M. Sandoval, 1875.

Díaz Mato, Ángel. "Las escuelas y los maestros de primeras letras siglo XIX". Revista de Formación del Profesorado e Investigación Educativa, núm. 23 (verano, 2010). 
Galván, Luz Elena. "La construcción de una historia, educación y educadores durante el porfiriato" en Indios, peones, hacendados y maestros: viejos actores para un México nuevo (1821-1943), ed. Martínez, Lucía, 175. México: UPN, 1994.

Gómez Serrano, Jesús. Aguascalientes en la historia: 1786-1920, Sociedad y Cultura, México: Gobierno del Estado de Aguascalientes-Instituto de investigaciones Dr. José María Luis Mora 1988.

Gutiérrez Garduño, María del Carmen. "De la educación de las niñas a la mujer educadora en el siglo XIX", en Miradas entorno a la educación de ayer, ed. Luz Elena Galván, 115-116. México: COMIE-U de G., 1997.

Granja Castro, Josefina. "Contar y clasificar a la infancia. Las categorías de la escolarización en las escuelas primarias de la ciudad de México 1870-1930", Revista Mexicana de Investigación Educativa, Vol. 14, Núm. 40 (México: Comie, 2009): 220.

H. Congreso del Estado, LII Legislatura. "Constitución política del estado de Aguascalientes de 1857", en Las Constituciones de Aguascalientes. México: 1986.

López Pérez, Oresta. "Currículum sexuado y poder: miradas de la educación liberal para hombres y mujeres durante la segunda mitad del siglo XIX en México". Revista Relaciones, núm. 113, vol. XXIX (invierno 2008): 36.

Meníndez, Rosalía. "Nacionalismo y patriotismo, fundamentos para la formación de ciudadanos: los libros de texto de civismo para educación primaria, 1876-1921", en Las disciplinas escolares y sus libros, México: Ciesas, UAEM, Juan Pablos Editores, 2010.

"Los proyectos educativos del siglo XIX: México y la construcción de la nación". Estudios 101, vol. X (México: UPN, verano, 2012): 197.

Ríos Zúñiga, Rosalina. Formar ciudadanos. Sociedad civil y modernización popular en Zacatecas, 1821-1853. México: UNAM -Valdés Editores, 2005.

Rives Iborra, Vicente. "La educación Aguascalentense en el Porfiriato" en Páginas sueltas. México: UAA-Centro de Ciencias Sociales y Humanidades, 2000. 
Omar Ruiz Trejo (zogancito@hotmail.com y omarutre@gmail.com) es licenciado en Historia por la Universidad Autónoma de Aguascalientes y actualmente es maestrante en Historia de la Educación por la Universidad Autónoma de Zacatecas "Francisco García Salinas" en el Programa Maestría-Doctorado en Historia, generación 2017-2018. La tesis para obtener el grado de maestro se titula El fomento a la instrucción pública de primeras letras en Aguascalientes 1867-1877. Así mismo, el autor se desempeña como docente impartiendo la materia de Historia de México en el Bachillerato de la Universidad Cuauhtémoc plantel Aguascalientes (UCA) (ORCID: 0000-0003-1227-5020) 